\title{
A Xq21.31 duplication without features of Prader-Willi syndrome
}

\author{
Manuel Castro-Gago • Laura Pérez-Gay • \\ Carmen Gómez-Lado · Francisco Barros-Angueira
}

Published online: 5 July 2012

(C) Springer Science+Business Media, LLC 2012

To the Editor,

We read with great interest the recent contribution by Pramyothin et al. [1], in Endocrine. They reported a 20 -year-old man diagnosed with 47, XXY during childhood, who presents an appearance similar to that of PraderWilli syndrome (PWS) with hypogonadism and gynecomastia, developmental delay, and short stature and obesity. Array-based comparative genome hybridization revealed duplication at Xq21.31 in addition to his abnormal karyotype. This duplication was also found in his mother who appeared normal. The authors hypothesized that the phenotype in this patient is a combination of both extra $\mathrm{X}$ chromosome and Xq21 duplication. On the other hand, Gabbertt et al. [2] have reported a 4-year-old male with an interstitial tandem duplication of Xq21.1-q21.31, maternally inherited, who presented with clinical features of PWS, and they conclude that duplication of chromosome $\mathrm{Xq}$ should be considered in the differential diagnosis of PWS, especially in males.

In this sense, we have been evaluating a 3-year-old (at first time) male with developmental delay, autism, hyperactive behavior, hand stereotypes, large ears, synophrys, excessive hair in back, pes planus/valgus, and body mass index in the 95th percentile (height in 50th percentile and weight in 75th percentile), and without features of PWS.

M. Castro-Gago $(\bowtie) \cdot$ L. Pérez-Gay · C. Gómez-Lado Servicio de Neuropediatría, Hospital Clínico Universitario, Facultad de Medicina, Universidad de Santiago de Compostela, La Choupana s/n, 15706 Santiago de Compostela, Spain e-mail: manuel.castro.gago@usc.es

F. Barros-Angueira

Fundación Pública Galega de Medicina Xenómica, Santiago de Compostela, Spain
No contributory family history (and non-consanguineous parents), normal pregnancy, and delivery. Previous studies were negative for the findings in brain MRI, karyotype, and fragile X syndrome. 7q11.23, 17p13, 22q11.2, and 22q13.3 microdeletions were tested (FISH) and were negative. Recently, he was diagnosed at the age of 9 years of Xq21.31 duplication (3.9 Mb) by means of Cytogenetics Whole-Genomics $2.7 \mathrm{M}$ array (Affymetrix): ArraysSNPs. In his mother, this genetic study was normal.

We hypothesized that the duplication of chromosome Xq21.31 should be considered also in males with the association of developmental delay, autism, and hyperactive behaviour without phenotypic features of PWS. This association may be related with that at least seven loci of mental retardation syndromes encompassing the duplication in the $\mathrm{Xq} 21.31$ region [1].

Conflict of interest The authors declared no potential conflicts of interest with respect to the research, authorship, and/or publication of this article.

\section{References}

1. P. Pramyothin, M. Pithukpakorn, R.F. Arakaki, A 47, XXY patient and Xq21.31 duplication with features of Prader-Willi syndrome: results of array-based comparative genomic hybridization. Endocrine 37, 379-382 (2010)

2. M.T. Gabbertt, G.B. Peters, J.M. Carmichael, A.P. Darmanian, F.A. Collins, Prader-Willi syndrome phenocopy due to duplication of Xq21.1-q21.31, with array CGH of the critical region. Clin. Genet. 23, 853-859 (2008) 